\title{
Pemanfaatan Citra Sentinel-2 untuk Studi Prakiraan Kerapatan Vegetasi di Kota Samarinda Menggunakan Metode Normalized Difference Vegetation Index (NDVI)
}

\author{
Dwi Agung Pramono* \\ Teknologi Geomatika, Politeknik \\ Pertanian Negeri Samarinda, \\ Samarinda, 75131 \\ dwapra@gmail.com \\ *Corresponding author
}

\author{
Dyah Widyasasi \\ Teknologi Geomatika, Politeknik \\ Pertanian Negeri Samarinda, \\ Samarinda, 75131 \\ widysh1@gmail.com \\ Dwinita Aquastini \\ Teknologi Geomatika, Politeknik \\ Pertanian Negeri Samarinda, \\ Samarinda, 75131 \\ dwiniaqua@yahoo.co.id
}

\author{
Oscariza Aristyas \\ Teknologi Geomatika, Politeknik \\ Pertanian Negeri Samarinda, \\ Samarinda, 75131 \\ oscariza08@gmail.com
}

\begin{abstract}
Abstrak - Tujuan dari penelitian ini adalah, untuk mengetahui tingkat kerapatan vegetasi di Kota Samarinda dan membuat peta kerapatan vegetasi di Kota Samarinda dengan memanfaatkan citra Sentinel-2.

Teknologi satelit berupa citra satelit Sentinel diolah menggunakan metode matematis Normalized Difference Vegetation Index (NDVI) guna mendapatkan luasan dan rentang kerapatan vegetasi berupa wilayah tidak bervegetasi, wilayah dengan vegetasi sangat rendah, wilayah dengan vegetasi rendah, wilayah dengan vegetasi sedang, serta wilayah dengan vegetasi tinggi di wilayah Kota Samarinda.

Berdasarkan hasil penelitian menunjukan bahwa citra Sentinel-2A dengan menggunakan band 8 dan band 4 serta metode matematis Normalized Difference Vegetation Index (NDVI) mampu untuk mengetahui tingkat kerapatan suatu vegetasi. Kota Samarinda memiliki total nilai rentang klasifikasi NDVI seluas $71.738,19$ Ha dengan tingkat kerapatan wilayah yang terdapat vegetasi seluas $66.355,89$ Ha dengan persentase $92,48 \%$ dan wilayah tidak bervegetasi seluas $5.382,30 \mathrm{Ha}$ dengan persentase 7,50\% serta diperoleh peta kerapatan vegetasi Kota Samarinda.
\end{abstract}

Kata Kunci-Sentinel-2, vegetasi, Kota Samarinda, NDVI

\section{PENDAhULUAN}

Kota merupakan sebuah permukiman yang terdiri dari bangunan atau rumah yang merupakan sebuah kesatuan tempat tinggal dari berbagai macam lapisan masyarakat. Setiap kota pasti selalu membangun fasilitas sarana dan prasarana guna meningkatkan kenyamanan warganya.
Setiap pembangunan terdapat manfaat serta resiko yang harus ditanggung apabila tidak direncanakan dengan matang. Berdasarkan Undang-Undang Nomor 26 Tahun 2007 tentang Tata Ruang, suatu perkotaan paling tidak harus menyediakan minimal sekitar 30\% Ruang Terbuka Hijau (RTH). Ruang Terbuka Hijau (RTH) memiliki faktor untuk menunjang ekosistem kota baik sebagai pemasok oksigen maupun sebagai area resapan air (Andini dkk., 2018).

Di era modern ini teknologi penginderaan jauh sering kali dimanfaatkan untuk berbagai macam kegiatan, salah satunya untuk mengetahui kerapatan vegetasi suatu wilayah. Salah satu teknologi pada bidang penginderaan jauh adalah satelit.

Sentinel-2 merupakan sebuah teknologi yang terdiri dari 2 satelit konstelasi yang dapat menghasilkan citra multispektral serta dapat dimanfaatkan dalam berbagai macam hal, salah satunya untuk mengetahui kerapatan suatu vegetasi. Cakupan wilayah dari citra satelit cukup luas sehingga dapat memperoleh banyak informasi dari suatu objek atau wilayah yang luas dengan cukup mudah. berikut:

Tujuan dilakukannya penelitian ini adalah sebagai

1. Mengetahui tingkat kerapatan vegetasi di wilayah Kota Samarinda.

2. Membuat peta kerapatan vegetasi wilayah Kota Samarinda dengan memanfaatkan citra Sentinel-2.

Hasil yang diharapkan adalah dapat memberikan manfaat berupa informasi mengenai ketersediaan Ruang Terbuka Hijau (RTH) di Kota Samarinda. 


\section{STUDI PUSTAKA}

Penelitian ini dilakukan di Kota Samarinda, Kalimantan Timur. Dengan objek penelitian yaitu Kota Samarinda. Waktu yang diperlukan untuk penelitian ini kurang lebih 4 bulan, yaitu mulai dari tanggal 6 April 2021 hingga 5 Juli 2021 yang meliputi kegiatan pengumpulan data, pengolahan data, dan penyusunan laporan

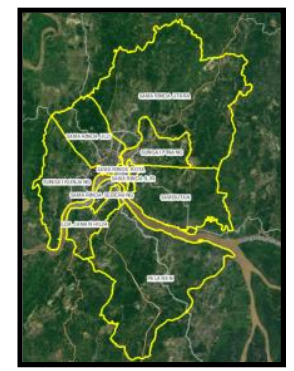

Gambar 1. Gambaran Lokasi Penelitian

Metode yang dipergunakan dalam penelitian ini adalah metode matematis menggunakan metode matematis Normalized Difference Vegetation Index $(N D V I)$ guna mendapatkan luasan dan rentang kerapatan vegetasi berupa wilayah tidak bervegetasi, wilayah dengan vegetasi sangat rendah, wilayah dengan vegetasi rendah, wilayah dengan vegetasi sedang, serta wilayah dengan vegetasi tinggi di wilayah Kota Samarinda.

Citra Sentinel-2A dilakukan koreksi radiometrik untuk memperbaiki nilai pixel citra agar sesuai dengan nilai sebenarnya; Selanjutnya dilakukan transformasi NDVI menggunakan band 8 dan band 4 sebagai variabel dengan menggunakan rumus : (NIR-RED) / (NIR+RED).

Setelah itu dilakukan cropping citra sesuai luas yang menjadi objek penelitian, selanjutnya diklasifikasikan dan dilakukan perhitungan luas kerapatan vegetasi dan dipetakan.

\section{HASIL DAN PEMBAHASAN}

Penelitian pemanfaatan Citra Sentinel-2A untuk Studi Prakiraan Kerapatan Vegetasi di Kota Samarinda Menggunakan Metode Normalized Difference Vegetation Index (NDVI) memberikan hasil antara lain sebagai berikut.

1. Tingkat Kerapatan Vegetasi Di Wilayah Kota Samarinda.

Tingkat kerapatan vegetasi di wilayah Kota Samarinda dianalisis dari peta prakiraan kerapatan vegetasi di Kota Samarinda, yang mana hasilnya dirangkum dalam tabel di bawah ini.

Tabel 1. Kelas Kerapatan Vegetasi Samarinda

\begin{tabular}{|c|c|c|c|c|}
\hline No & $\begin{array}{c}\text { Kelas } \\
\text { Kerapatan }\end{array}$ & $\begin{array}{c}\text { Nilai } \\
\text { Interval }\end{array}$ & Persentase & Luasan (Ha) \\
\hline \multirow{3}{*}{1} & Tidak Ada & 0,12 & $7,50 \%$ & \multirow{3}{*}{$5.382,30$} \\
\hline & Vegetasi & & & \\
\hline & Vegetasi & $0,12-$ & $8,90 \%$ & \\
\hline \multirow[t]{2}{*}{2} & Sangat Rendah & 0,22 & & \multirow[t]{2}{*}{$6.386,36$} \\
\hline & Vegetasi & $0,22-$ & $18,07 \%$ & \\
\hline \multirow[t]{2}{*}{3} & Rendah & 0,42 & & \multirow[t]{2}{*}{$12.967,37$} \\
\hline & Vegetasi & $0,42-$ & $62,54 \%$ & \\
\hline \multirow{2}{*}{4} & Sedang & 0,72 & & \multirow{2}{*}{$44.871,47$} \\
\hline & Vegetasi & $0,72-1$ & $2,97 \%$ & \\
\hline \multirow[t]{2}{*}{5} & Tinggi & & & $2.130,69$ \\
\hline & & & Total & $71.738,19$ \\
\hline
\end{tabular}

\begin{tabular}{|c|c|c|c|c|}
\hline $\begin{array}{l}\mathrm{N} \\
\mathrm{o}\end{array}$ & Kelas Kerapatan & $\begin{array}{c}\text { Nilai } \\
\text { Interval }\end{array}$ & Persentase & Luas (Ha) \\
\hline \multicolumn{5}{|c|}{ A. Samarinda Utara } \\
\hline 1 & $\begin{array}{l}\text { Tidak Ada } \\
\text { Vegetasi }\end{array}$ & $<0,12$ & $0,39 \%$ & 89,74 \\
\hline 2 & $\begin{array}{l}\text { Vegetasi Sangat } \\
\text { Rendah }\end{array}$ & $\begin{array}{l}0,12- \\
0,22\end{array}$ & $2,65 \%$ & 604,52 \\
\hline 3 & Vegetasi Rendah & $\begin{array}{l}0,22- \\
0,42\end{array}$ & $25,27 \%$ & $5.755,71$ \\
\hline 4 & Vegetasi Sedang & $\begin{array}{l}0,42- \\
0,72\end{array}$ & $60,93 \%$ & $13.876,17$ \\
\hline \multirow[t]{2}{*}{5} & Vegetasi Tinggi & $1^{0,72-}$ & $10,74 \%$ & $2.446,20$ \\
\hline & & & Total & $22.772,34$ \\
\hline \multicolumn{5}{|c|}{ B. Sungai Pinang } \\
\hline 1 & $\begin{array}{l}\text { Tidak Ada } \\
\text { Vegetasi }\end{array}$ & $<0,12$ & $0,18 \%$ & 6,05 \\
\hline 2 & $\begin{array}{l}\text { Vegetasi Sangat } \\
\text { Rendah }\end{array}$ & $\begin{array}{l}0,12- \\
0,22\end{array}$ & $7,84 \%$ & 259,82 \\
\hline 3 & Vegetasi Rendah & $\begin{array}{l}0,22- \\
0,42\end{array}$ & $65,99 \%$ & $2.184,79$ \\
\hline 4 & Vegetasi Sedang & $\begin{array}{l}0,42- \\
0,72\end{array}$ & $25,96 \%$ & 859,50 \\
\hline \multirow[t]{2}{*}{5} & Vegetasi Tinggi & $1^{0,72-}$ & $0 \%$ & 0,17 \\
\hline & & & Total & $3.310,33$ \\
\hline
\end{tabular}

Hasil perhitungan dengan menggunakan metode NDVI berdasarkan rentang klasifikasi NDVI pada 10 (sepuluh) kecamatan yang ada di kota Samarinda disajikan dalam Tabel 2 berikut.

\begin{tabular}{|c|c|c|c|c|}
\hline \multicolumn{5}{|c|}{ C. Samarinda Ulu } \\
\hline 1 & Tidak Ada & \multirow[t]{2}{*}{$<0,12$} & $0,69 \%$ & 34,62 \\
\hline & Vegetasi & & & \\
\hline \multirow[t]{2}{*}{2} & Vegetasi Sangat & 0,12 & $8,48 \%$ & 421,32 \\
\hline & Rendah & 0,22 & & \\
\hline \multirow[t]{2}{*}{3} & Vegetasi Rendah & 0,22 & $23,09 \%$ & $1.146,39$ \\
\hline & & 0,42 & & \\
\hline \multirow[t]{2}{*}{4} & Vegetasi Sedang & 0,42 & $60,31 \%$ & $2.993,29$ \\
\hline & & 0,72 & & \\
\hline \multirow[t]{3}{*}{5} & Vegetasi Tinggi & 0,72 & $7,40 \%$ & 367,33 \\
\hline & & 1 & & \\
\hline & & & Total & $4.962,95$ \\
\hline No & $\begin{array}{c}\text { Kelas } \\
\text { Kerapatan }\end{array}$ & $\begin{array}{c}\text { Nilai } \\
\text { Interval }\end{array}$ & Persentase & Luas (Ha) \\
\hline \multicolumn{5}{|c|}{ D. Sambutan } \\
\hline 1 & $\begin{array}{l}\text { Tidak Ada } \\
\text { Vegetasi }\end{array}$ & $<0,12$ & $1,26 \%$ & 136,36 \\
\hline \multirow[t]{2}{*}{2} & Vegetasi Sangat & $0,12-$ & $3,39 \%$ & 367,19 \\
\hline & Rendah & 0,22 & & \\
\hline \multirow[t]{2}{*}{3} & Vegetasi & $0,22-$ & $33,81 \%$ & $3.656,04$ \\
\hline & Rendah & 0,42 & & \\
\hline \multirow[t]{2}{*}{4} & Vegetasi & $0,42-$ & $61,16 \%$ & $6.612,10$ \\
\hline & Sedang & 0,72 & & \\
\hline \multirow[t]{2}{*}{5} & Vegetasi Tinggi & $0,72-$ & $0,36 \%$ & 39,23 \\
\hline & & & Total & $10.810,92$ \\
\hline
\end{tabular}




\begin{tabular}{|c|c|c|c|c|}
\hline \multicolumn{5}{|c|}{ E. Samarinda Ilir } \\
\hline 1 & $\begin{array}{l}\text { Tidak Ada } \\
\text { Vegetasi }\end{array}$ & $<0,12$ & $19,73 \%$ & 87,64 \\
\hline 2 & $\begin{array}{l}\text { Vegetasi Sangat } \\
\text { Rendah }\end{array}$ & $\begin{array}{l}0,12- \\
0,22\end{array}$ & $19,55 \%$ & 86,83 \\
\hline 3 & $\begin{array}{l}\text { Vegetasi } \\
\text { Rendah }\end{array}$ & $\begin{array}{l}0,22- \\
0,42\end{array}$ & $18,06 \%$ & 80,23 \\
\hline 4 & $\begin{array}{l}\text { Vegetasi } \\
\text { Sedang }\end{array}$ & $\begin{array}{l}0,42- \\
0,72\end{array}$ & $42,62 \%$ & 189,24 \\
\hline 5 & Vegetasi Tinggi & $\begin{array}{l}0,72- \\
1\end{array}$ & $0,03 \%$ & 0,16 \\
\hline & & & Total & 444,01 \\
\hline \multicolumn{5}{|c|}{ F. Samarinda Kota } \\
\hline 1 & $\begin{array}{l}\text { Tidak Ada } \\
\text { Vegetasi }\end{array}$ & $<0,12$ & $49,44 \%$ & 144,30 \\
\hline 2 & $\begin{array}{l}\text { Vegetasi Sangat } \\
\text { Rendah }\end{array}$ & $\begin{array}{l}0,12- \\
0,22\end{array}$ & $25,76 \%$ & 75,18 \\
\hline 3 & $\begin{array}{l}\text { Vegetasi } \\
\text { Rendah }\end{array}$ & $\begin{array}{l}0,22- \\
0,42\end{array}$ & $17,62 \%$ & 51,43 \\
\hline 4 & $\begin{array}{l}\text { Vegetasi } \\
\text { Sedang }\end{array}$ & $\begin{array}{l}0,42- \\
0,72\end{array}$ & $7,16 \%$ & 20,91 \\
\hline 5 & Vegetasi Tinggi & $\begin{array}{l}0,72- \\
1\end{array}$ & $0 \%$ & 0 \\
\hline & & & Total & 291,82 \\
\hline \multicolumn{5}{|c|}{ G. Sungai Kunjang } \\
\hline 1 & $\begin{array}{l}\text { Tidak Ada } \\
\text { Vegetasi }\end{array}$ & $<0,12$ & $0,38 \%$ & 26,02 \\
\hline 2 & $\begin{array}{l}\text { Vegetasi Sangat } \\
\text { Rendah }\end{array}$ & $\begin{array}{l}0,12- \\
0,22\end{array}$ & $5,34 \%$ & 359,28 \\
\hline 3 & $\begin{array}{l}\text { Vegetasi } \\
\text { Rendah }\end{array}$ & $\begin{array}{l}0,22- \\
0,42\end{array}$ & $36,20 \%$ & $2.431,54$ \\
\hline 4 & $\begin{array}{l}\text { Vegetasi } \\
\text { Sedang }\end{array}$ & $\begin{array}{l}0,42- \\
0,72\end{array}$ & $55,97 \%$ & $3.758,98$ \\
\hline 5 & Vegetasi Tinggi & $\begin{array}{l}0,72- \\
1\end{array}$ & $2,09 \%$ & 140,68 \\
\hline & & & Total & $6.716,05$ \\
\hline \multicolumn{5}{|c|}{ H. Samarinda Seberang } \\
\hline 1 & $\begin{array}{l}\text { Tidak Ada } \\
\text { Vegetasi }\end{array}$ & $<0,12$ & $12,29 \%$ & 98,84 \\
\hline 2 & $\begin{array}{l}\text { Vegetasi Sangat } \\
\text { Rendah }\end{array}$ & $\begin{array}{l}0,12- \\
0,22\end{array}$ & $19,14 \%$ & 153,89 \\
\hline 3 & $\begin{array}{l}\text { Vegetasi } \\
\text { Rendah }\end{array}$ & $\begin{array}{l}0,22- \\
0,42\end{array}$ & $24,78 \%$ & 199,23 \\
\hline 4 & $\begin{array}{l}\text { Vegetasi } \\
\text { Sedang }\end{array}$ & $\begin{array}{l}0,42- \\
0,72\end{array}$ & $43,72 \%$ & 351,48 \\
\hline 5 & Vegetasi Tinggi & $\begin{array}{l}0,72- \\
1\end{array}$ & $0,05 \%$ & 0,45 \\
\hline & & & Total & 803,89 \\
\hline No & $\begin{array}{c}\text { Kelas } \\
\text { Kerapatan } \\
\end{array}$ & $\begin{array}{c}\text { Nilai } \\
\text { Interval }\end{array}$ & Persentase & Luas (Ha) \\
\hline
\end{tabular}

\begin{tabular}{|c|c|c|c|c|}
\hline \multicolumn{5}{|c|}{ I. Loa Janan Ilir } \\
\hline 1 & $\begin{array}{l}\text { Tidak Ada } \\
\text { Vegetasi }\end{array}$ & $<0,12$ & $49,44 \%$ & 104,33 \\
\hline 2 & $\begin{array}{l}\text { Vegetasi Sangat } \\
\text { Rendah }\end{array}$ & $\begin{array}{l}0,12- \\
0,22\end{array}$ & $25,76 \%$ & 311,33 \\
\hline 3 & $\begin{array}{l}\text { Vegetasi } \\
\text { Rendah }\end{array}$ & $\begin{array}{l}0,22- \\
0,42\end{array}$ & $17,62 \%$ & 630,31 \\
\hline 4 & $\begin{array}{l}\text { Vegetasi } \\
\text { Sedang }\end{array}$ & $\begin{array}{l}0,42- \\
0,72\end{array}$ & $7,16 \%$ & $1.783,95$ \\
\hline 5 & Vegetasi Tinggi & $\begin{array}{l}0,72- \\
1\end{array}$ & $0 \%$ & 27,98 \\
\hline & & \multicolumn{2}{|c|}{ Total } & $2.857,09$ \\
\hline \multicolumn{5}{|c|}{ J. Palaran } \\
\hline 1 & $\begin{array}{l}\text { Tidak Ada } \\
\text { Vegetasi }\end{array}$ & $<0,12$ & $1,18 \%$ & 221,64 \\
\hline 2 & $\begin{array}{l}\text { Vegetasi Sangat } \\
\text { Rendah }\end{array}$ & $\begin{array}{l}0,12- \\
0,22\end{array}$ & $5,96 \%$ & $1.119,01$ \\
\hline 3 & $\begin{array}{l}\text { Vegetasi } \\
\text { Rendah }\end{array}$ & $\begin{array}{l}0,22- \\
0,42\end{array}$ & $17,98 \%$ & $3.375,18$ \\
\hline 4 & $\begin{array}{l}\text { Vegetasi } \\
\text { Sedang }\end{array}$ & $\begin{array}{l}0,42- \\
0,72\end{array}$ & $57,25 \%$ & $10.748,38$ \\
\hline 5 & Vegetasi Tinggi & $0,72-$ & $17,95 \%$ & $3.370,82$ \\
\hline
\end{tabular}

1 Total $18.771,85$

2. Peta Kerapatan Vegetasi Wilayah Kota Samarinda

Peta prakiraan kerapatan vegetasi di Kota Samarinda yang dibuat dengan menggunakan citra Sentinel-2A dengan metode NDVI disajikan pada gambar di bawah ini.

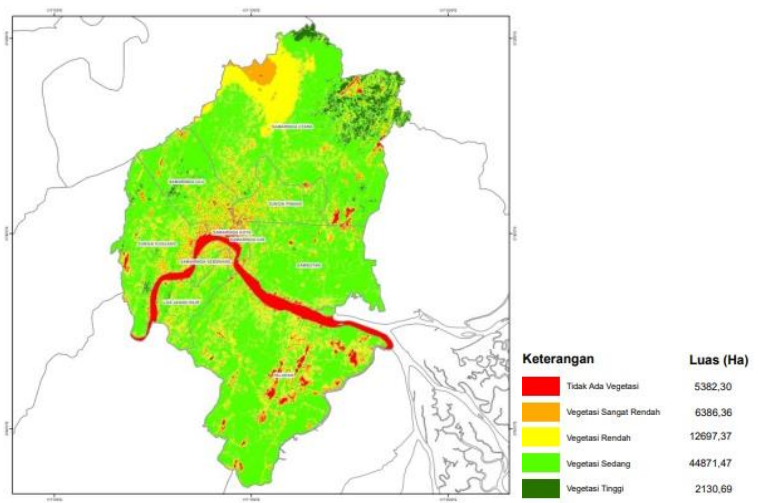

Gambar 2. Peta Kerapatan Vegetasi Wilayah Kota Samarinda

1. Tingkat Kerapatan Vegetasi Di Wilayah Kota Samarinda.

Dari hasil di atas dapat diketahui bahwa kecamatan di Kota Samarinda yang memiliki total nilai rentang klasifikasi NDVI terluas terdapat pada kecamatan Samarinda Utara, sedangkan untuk total nilai rentang klasifikasi NDVI terkecil terdapat pada kecamatan Samarinda Kota.

Berdasarkan data di atas dapat diketahui bahwa wilayah yang tidak terdapat vegetasi di Kota Samarinda yaitu seluas 5.382,30 Ha sedangkan untuk wilayah yang terdapat vegetasi apabila ditotalkan akan diperoleh luas yaitu 66.355,89 Ha. Berdasarkan nilai persentase, Kota Samarinda memiliki wilayah tidak bervegetasi yaitu $7,50 \%$ sedangkan untuk wilayah yang terdapat vegetasi apabila di totalkan yaitu $92,48 \%$. Adanya wilayah yang tidak terdapat vegetasi dapat diakibatkan oleh tingginya tingkat pembangunan di wilayah tersebut atau adanya galian-galian tambang yang belum ditutup kembali, untuk wilayah yang memiliki tingkat vegetasi tinggi menandakan bahwa wilayah tersebut masih memiliki tingkat pembangunan yang rendah. Asumsi mengenai Ruang Terbuka Hijau di Kota Samarinda di proyeksikan pada wilayah dengan rentang kerapatan vegetasi tinggi, diasumsikan bahwa wilayah tersebut merupakan kawasan yang terdiri dari vegetasi berkayu.

1. Peta Kerapatan Vegetasi Wilayah Kota Samarinda.

Perhitungan kerapatan vegetasi dilakukan dengan metode Normalized Difference Vegetation Index (NDVI), dengan menggunakan band 8 dan band 4 pada data citra Sentinel-2A yang direkam tanggal 8 Januari 2020 sebagai variabel perhitungannya. Data citra Sentinel-2A tanggal 8 Januari 2020 digunakan sebagai pertimbangan karena memiliki tutupan awan yang cukup rendah. 
Citra Sentinel-2A harus melalui proses koreksi radiometrik terlebih dahulu sebelum dilakukan proses transformasi Normalized Difference Vegetation Index (NDVI). Koreksi radiometrik dilakukan untuk memperbaiki nilai pixel yang berubah akibat adanya gangguan pada atmosfer saat proses perekaman. Proses koreksi radiometrik ini dilakukan dengan bantuan Software Quantum GIS (QGIS).

Luas dari rentang klasifikasi tersebut dihitung dengan menggunakan fitur Calculate Geometry pada ArcMap.

\section{KESIMPULAN}

Kesimpulan yang dapat diambil pada penelitian ini adalah:

1. Peta kerapatan vegetasi Kota Samarinda dapat dibuat menggunakan skala 1:160.000, serta memberikan informasi berupa sebaran tingkat kerapatan vegetasi pada masing-masing kecamatan di Kota Samarinda.

2. Dengan menggunakan band 8 dan band 4 pada citra Sentinel-2A dapat diketahui nilai kerapatan vegetasi di Kota Samarinda, pada rentang wilayah tidak terdapat vegetasi seluas 5.382,30 $\mathrm{Ha}$ dengan persentase $7,50 \%$ dan wilayah dengan rentang terdapat vegetasi apabila ditotalkan seluas $66.355,89$ Ha dengan persentase $92,48 \%$, menggunakan metode Normalized Difference Vegetation Index (NDVI) dengan rentang klasifikasi, tidak ada vegetasi, vegetasi sangat rendah, vegetasi rendah, vegetasi sedang, dan vegetasi tinggi.

\section{DAFTAR PUSTAKA}

Agoes, H.F., Irawan, F.A., Marlianisya. R. 2018. "Interpretasi Citra Digital Penginderaan Jauh Estimasi Hasil Panen Padi". Jurnal INTEKNA, $18(1), 1-66$.

Anonim. 2020. "Hasil Sensus Penduduk 2020". https://samarindakota.bps.go.id/pressrelease/2021/0 1/26/101/hasil-sensus-penduduk-2020.html (diunduh 16 Juni 2021).

Anonim. $2016 . \quad$ "Deskripsi Samarinda". https://sippa.ciptakarya.pu.go.id/sippa_online/ws_fi le/dokumen/rpi2jm/DOCRPIJM_147977924102_B AB_II_RPJMD_19062016.pdf (diunduh 25 Juni 2021)

Ardiananda, C.S., I. Virgianti., E. Wahyuni., Indra M.Q., D. Juwitaningsih. 2017. "Geografi Modul 2".

Awaliyan, M.R. dan Y.B. Sulistioadi. 2018. "Klasifikasi Penutupan Lahan Pada Citra Satelit Sentinel-2a Dengan Metode Tree Algorithm". ULIN: Jurnal Hutan Tropis, 2(2), 98-104.

Andini, S.W., Y. Prasetyo., A. Sukmono. 2018. "Analisis Sebaran Vegetasi Dengan Citra Satelit Sentinel Menggunakan Metode NDVI Dan Segmentasi". Jurnal Geodesi Undip. 7(1), 14-24.

Darmawan, A., Sudeng P.H., T.Santoso. 2018. "Buku
Ajar Penginderaan Jauh untuk Kehutanan". 1-177.

Molidena, E. dan As-Syakur, A.R. 2012. "Karekteristik Pola Spektral Vegetasi Hutan dan Tanaman Industri Berdasarkan Data Penginderaan Jauh". Prosiding Pertemuan Ilmiah Tahunan MAPIN XIX, 1-5.

Oktaviani, N. dan Kusuma, H.A. 2017. "Pengenalan Citra Satelit Sentinel-2 Untuk Pemetaan Kelautan". Oseana. 42(3), 40-55.

Putranto, E.D. 2020. "Perbedaan Interpretasi Citra Radar Dengan Citra Foto Udara". 1-7.

Permatasari, D. 2012. "Tekstur Berbasis Pengolahan Citra Digital Classification System of Corn Kernel Quality based on Texture Using Digital Image Processing".

Prayogo, L.M. 2020. "Quantum GIS 3.14 [Basic]". Vol. 1 , Issue November.

Wahyudi., Brotopuspito, K. S., I. Suyanto. 2020. "Rancang Bangun Sistem Akuisisi Data Infra Merah Menggunakan Pesawat Udara Tanpa Awak (UAV) untuk Memantau Aktivitas Gunungapi". Jurnal Fisika Indonesia. Vol. 23, Issue 1.

Wulandari, N. 2020. "Penggunaan Metode NDVI (Normalized Difference Vegetation Index) Dan Savi (Soil Adjusted Vegetation Index) Untuk Mengetahui Ketersediaan Ruang Terbuka". 